\title{
COMPARAÇÃO DE EFICIÊNCIA ENTRE AS INSTITUIÇÕES DE ENSINO SUPERIOR PÚBLICAS E PRIVADAS NO DESEMPENHO ACADÊMICO DOS ALUNOS CONCLUINTES EM CIÊNCIAS ECONÔMICAS ${ }^{1}$
}

\author{
Felipe César Marques² \\ Guilherme Rubim Davoglio ${ }^{3}$ \\ Marcia Regina Gabardo da Camara ${ }^{4}$ \\ Sidnei Pereira do Nascimento ${ }^{5}$ \\ Carlos Roberto Ferreira ${ }^{6}$
}

\begin{abstract}
O objetivo do trabalho é avaliar o desempenho das instituições de ensino superior (IES) públicas e privadas em relação a sua capacidade de agregar conhecimento acadêmico aos alunos concluintes em ciências econômicas, com base nas notas do Exame Nacional de Desempenho dos Estudantes (Enade) em 2012 e 2015. 0 estudo contribui com a literatura, ao utilizar uma nova abordagem, que decompõe a análise envoltória de dados em dois componentes: um relativo ao desempenho do aluno, e outro relacionado à eficiência das IES. Aplica-se também a técnica de mínimos quadrados ordinários para o controle dos fatores socioeconômicos dos alunos. Para a obtenção de fronteiras de eficiência robustas, foi utilizado o método jackstrap de identificação de outliers. Os resultados indicam não haver diferenças significativas de eficiência entre as categorias administrativas, tanto entre os alunos, quanto entre as instituições. Verifica-se também a menor eficiência média de alunos, quando comparada com a eficiência média das IES.
\end{abstract}

Palavras-chave: análise envoltória de dados; desempenho acadêmico; educação pública e privada.

\section{EFFICIENCY COMPARISON BETWEEN PUBLIC AND PRIVATE HIGHER EDUCATION INSTITUTIONS IN THE ACADEMIC PERFORMANCE OF ECONOMICS SENIOR STUDENTS}

The aim of the paper is to evaluate the performance of public and private higher education institutions (HEI) regarding its capacity to aggregate academic knowledge to economics senior students, based in the Enade scores during 2012 and 2015. The study contributes with the literature by using a new approach, which decomposes the Data Envelopment Analysis in two components: one concerned to pupil's performance and another one related to HEls efficiency. It is also applied Ordinary Least Squares to control socioeconomic factors from the students. In order to obtain a robust efficiency frontier, it was used the Jackstrap method for outlier detection. The results show that there are no significant differences in efficiency between the administrative categories, from both students and institution point of view. It was also verified the smaller average efficiency of the students when compared with HEl's efficiency.

Keywords: data envelopment analysis; academic performance; public and private education.

1. DOl: http://dx.doi.org/10.38116/ppp54art07

2.Professor do Departamento de Economia da Universidade Estadual de Londrina (UEL).E-mail: <felipe311.marques@ gmail.com>.

3. Professor da Fatec Jaboticabal Nilo De Stéfani.E-mail: <guilherme_davoglio@hotmail.com>.

4. Professora do Departamento de Economia da UEL.E-mail:<mgabardo@uel.br>.

5. Professor do Departamento de Economia da UEL.E-mail:<sidnei@uel.br>.

6. Professor do Departamento de Economia da UEL.E-mail: <robert@uel.br>. 


\section{COMPARACIÓN DE EFICIENCIA ENTRE LAS INSTITUCIONES DE EDUCACIÓN SUPERIOR PÚBLICAS Y PRIVADAS EN EL DESEMPEÑO ACADÉMICO DE LOS ALUMNOS EN CIENCIAS ECONÓMICAS}

El objetivo de la investigación es evaluar el desempeño de las instituciones de educación superior (IES) públicas y privadas en relación con su capacidad de agregar conocimiento académico para los estudiantes graduados en economía, basado en las notas del Enade 2012 y 2015 . El estudio contribuye con la literatura por utilizar un nuevo abordaje que desagrega la Análisis Envolvente de Datos en dos componentes: uno para el desempeño del estudiante, y otro relacionado con la eficiencia de las IES. También se aplica la técnica de los Mínimos Cuadrados para el control de los factores socioeconómico de los estudiantes. Para obtener fronteras robustas de eficiencia se usa el método Jackstrap para identificación de outliers. Los resultados muestran que no hay diferencias significativas de eficiencia entre las categorías administrativas, tanto entre estudiantes como entre instituciones. Verificase también la eficiencia promedio más pequeña de los estudiantes, si comparada con las IES.

Palabras clave: análisis envolvente de datos; desempeño académico; educación pública y privada.

\section{COMPARAISON D'EFFICIENCE ENTRE LES ÉTABLISSEMENTS D'ENSEIGNEMENT SUPERIEUR PUBLICS ET PRIVÉS DANS LA PERFORMANCE ACADEMIQUE DES ELEVES EN SCIENCES ECONOMIQUES}

L'objectif de cet étude est d'évaluer la performance des établissements d'enseignement supérieur (EES) publics et privés sur sa capacité d'agréger des connaissances académiques aux étudiants qui términent les cours en sciences économiques, basé sur les notes d'Enade 2012 et 2015. La recherche contribue avec la littérature en utilisant une nouvelle approche que décompose I'Analyse par Enveloppement des Données en deux éléments : I'un relatif à la performance de l'étudiant, et I'autre lié à l'efficience des EES. II est utilisé aussi la méthode des Moindres Carrés Ordinaire pour le contrôle des facteurs socio-économique des élèves. Pour obtenir la frontière efficiente robuste, on utilise aussi la méthode Jackstrap d'identification des outliers. Les résultats indiquent qu'il n'y a pas de differences significatives d'efficience pour les catégories administratives, soit entre les élèves, soit entre les établissements. On vérifie aussi l'efficience moyenne la plus petite des étudiants quand comparé avec celle des EES.

Mots-clés: analyse par enveloppement des données; performance académique; éducation public et privée.

JEL: $C 14 ; 121$.

\section{INTRODUÇÃO}

No decurso do século XX, houve duas grandes fases de expansão no ensino superior no Brasil. A primeira delas, entre 1964 e 1980, durante o regime militar, período no qual o número de matrículas aumentou em quase dez vezes; a segunda fase de expansão correspondeu ao período pós-1995, e teve como principal característica o forte crescimento das instituiçôes privadas, em detrimento das instituiçóes públicas, em consonância com as políticas de liberalismo econômico e austeridade fiscal do período. O setor passou ainda por um processo de desregulamentação e flexibilização dos requisitos para a criação de cursos e instituiçóes (Michelotto, Coelho e Zainko, 2006; Corbucci, 2004). 
Mais recentemente, de acordo com Pfeifer e Giareta (2009), a tendência foi de continuidade no processo de expansão da educação superior, mantendo-se as mesmas bases de tratamento com relação ao ensino privado, juntamente com a ampliação da rede pública, principalmente via investimento em instituiçóes de ensino superior (IES) federais e estaduais. Costa et al. (2010) elencam, entre as principais políticas públicas do governo federal para a expansão do ensino superior no período recente: o Programa de Apoio ao Plano de Reestruturaçáo e Expansão das Universidades Federais (Reuni), o Programa Universidade para Todos (Prouni) e o Fundo de Financiamento Estudantil (Fies). Em 2015, segundo dados do Instituto Nacional de Estudos e Pesquisas Educacionais Anísio Teixeira (Inep), $73 \%$ das matrículas no ensino superior foram realizadas em instituiçóes privadas (Inep, 2016).

Diante do panorama atual de expansão do ensino superior, especialmente na esfera privada, o objetivo do trabalho é avaliar o desempenho das IES públicas e privadas em relação a sua capacidade de agregar conhecimento acadêmico aos alunos, com enfoque no curso de ciências econômicas, e tomando-se como base as duas últimas provas do Exame Nacional de Desempenho dos Estudantes (Enade). A proposta deste trabalho já foi abordada previamente em alguns estudos, e, em geral, os resultados têm indicado a maior eficiência de IES privadas (Façanha e Marinho, 2001; França, 2004; Coelho Júnior, 2011; Wagner, 2011). No entanto, estes trabalhos ignoram tanto o papel atribuído aos alunos no processo educacional, considerando que toda ineficiência encontrada é consequência da atuação das IES, quanto a diversidade de cursos (e consequentemente de eficiência) que existe em uma instituição, criando-se, dessa forma, uma lacuna a ser preenchida.

O presente trabalho, portanto, contribui com a literatura atual ao empregar uma nova abordagem, proposta por Thanassoulis e Portela (2002), decompondo a eficiência em fatores relacionados ao desempenho do aluno e à eficiência da IES, com enfoque em um único curso. $\mathrm{O}$ trabalho também leva em conta a sensibilidade da análise de eficiência diante da presença de outliers, por meio da técnica Jackstrap, conforme Sousa e Stosic (2003).

Algumas características dos cursos de ciências econômicas justificam sua adoção como objeto de estudo. Primeiramente, devido a sua heterogeneidade. São analisados 54 IES públicas e 48 IES privadas em 2012; e 60 IES públicas e 39 IES privadas em 2015. Ademais, existem instituições grandes e pequenas em relação ao número de alunos (são avaliados IES com 25 a 342 alunos concluintes). E, apesar de heterogêneo, trata-se de um curso com um número relativamente baixo de alunos (aproximadamente 7 mil alunos são utilizados na análise em ambos os anos), possibilitando a aplicação de ferramentas computacionalmente intensivas, como o Jackstrap, com facilidade. Os anos de 2012 e 2015 foram enfocados por serem os mais recentes com disponibilidade de dados para o curso de economia. 
Além desta introdução, o estudo contém mais quatro seções. Na segunda seção, descreve-se a forma de mensurar a eficiência por meio da análise envoltória de dados, bem como suas aplicaçóes no ensino superior, além de se apresentar a técnica de desagregação da eficiência técnica entre alunos e instituiçóes e o método Jackstrap de detecção de outliers. A seção seguinte descreve a metodologia do trabalho e a forma de obtenção e tratamento dos dados. A quarta seção mostra os resultados do trabalho e a discussão com outros trabalhos da área. A última seção apresenta as consideraçóes finais do estudo, incluindo potenciais oportunidades para futuros trabalhos a respeito do tema.

\section{A MENSURAÇÃO DA EFICIÊNCIA TÉCNICA POR MEIO DA ANÁLISE ENVOLTÓRIA DE DADOS}

Intuitivamente, a técnica da análise envoltória de dados (data envelopment analysis DEA) parte do pressuposto da existência de um número finito $(Q)$ de unidades tomadoras de decisão (decision making units - DMUs), que realizam atividades similares, utilizando diferentes combinaçóes dos $N$ insumos disponíveis, e convertendo-os em $M$ diferentes produtos. Estas unidades são então comparadas entre si e avaliadas de acordo com sua eficiência relativa. $\mathrm{O}$ modelo, inicialmente proposto por Charnes, Cooper e Rhodes (1978), apresenta orientação a insumos e pressupóe retornos constantes à escala, e é dado pelo seguinte problema de maximização:

$$
\begin{array}{ll}
\operatorname{Max}_{\{u, v\}:} & \theta=u^{\prime} q_{i} / v^{\prime} x_{i} \\
\text { Sujeito a: } & u^{\prime} q_{j} / v^{\prime} x_{j} \leq 1 \quad j=1,2, \ldots, I, \\
& u, v \quad \geq 0
\end{array}
$$

No modelo, $q_{i}$ representa o vetor de produtos e $x_{i}$, o vetor de insumos da $i$-ésima DMU; $u$ e $v$ são, respectivamente, os vetores de ponderação dos produtos e dos insumos. O problema envolve entâo encontrar valores para $u$ e $v$, de forma a se maximizar a medida de eficiência da $i$-ésima DMU, representada por $\theta$. O processo é então realizado para cada um das I DMUs analisadas. Este problema matemático não linear pode ser reescrito em uma forma linearizada equivalente, acrescentando-se a restrição $v^{\prime} x_{i}=1$. O novo problema, conhecido como forma multiplicativa, passa a ser:

$$
\begin{array}{ll}
\operatorname{Max}_{\{u, v\}:} & \theta=u^{\prime} q_{i} \\
\text { Sujeito a: } & v^{\prime} x_{i}=1 \\
& u^{\prime} q_{j}-v^{\prime} x_{j} \leq 0 \quad j=1,2, \ldots, I, \\
& u, v \quad \geq 0
\end{array}
$$


Segundo o teorema da dualidade, é possível derivar, a partir da equação (2), sua forma envelopada, cuja principal vantagem é o desenvolvimento de um problema com menor número de restriçôes. Essa forma é também conhecida por modelo DEA-CCR, calculado da seguinte maneira:

$$
\begin{array}{ll}
\operatorname{Min}_{\{\theta, \lambda\}}: & \theta \\
\text { Sujeito } a: & -q_{i}+Q \lambda \geq 0, \\
& \theta x_{i}-X \lambda \geq 0, \\
& \lambda \geq 0
\end{array}
$$

Na equação (3), $Q$ representa a matriz $N \mathrm{x} I$ formada pelos vetores de insumo de todas as DMUs avaliadas, e $X$ é a matriz $M \mathrm{x} I$ dos vetores de produtos das DMUs. Por fim, $\lambda$ é o novo vetor de pesos a ser calculado. Posteriormente, Banker, Charnes e Cooper (1984) expandiram o modelo DEA-CCR, incluindo-se a possibilidade do cálculo de retornos variáveis de escala, ao se incluir uma restrição de convexidade: $\Pi^{\prime} \lambda=1$, no qual $\Pi$ é um vetor composto por valores unitários. Este modelo, denominado DEA-BCC, é dado por:

$$
\begin{array}{ll}
\operatorname{Min}_{\{\theta, \lambda\}}: & \theta \\
\text { Sujeito } a: & -q_{i}+Q \lambda \geq 0, \\
& \theta x_{i}-X \lambda \geq 0, \\
& \Pi^{\prime} \lambda=1, \\
& \lambda \geq 0
\end{array}
$$

Finalmente, o problema pode ser facilmente estendido à orientação a produtos, realizando-se o problema de maximização, definido como:

$$
\begin{array}{ll}
\operatorname{Max}_{\{\phi, \lambda\}}: & \phi \\
\text { Sujeito a: } & -\phi q_{i}+Q \lambda \geq 0, \\
& x_{i}-X \lambda \geq 0, \\
& \Pi^{\prime} \lambda=1, \\
& \lambda \geq 0
\end{array}
$$

A técnica do DEA é considerada uma metodologia atrativa na avaliação do ensino superior (Johnes, 2006a), devido a uma série de fatores, tais como a capacidade de utilização de múltiplos insumos e produtos, sem a necessidade de atribuição de pesos ou de uma forma funcional específica (Souza e Stosic, 2015; Thanassoulis e Portela, 2002). 
Entre os trabalhos que avaliam o ensino superior seguindo a abordagem DEA, pode-se citar Abbott e Doucouliagos (2002), que levam em consideração a pressão financeira sofrida pelos Estados, e mostram que, independentemente do mix de input e output, as universidades australianas, como um todo, registraram altos níveis de eficiência. Johnes (2006b) também atesta o nível alto de eficiência das universidades britânicas. Estudos semelhantes também foram elaborados para diferentes países, como Estados Unidos, em Ahn e Seiford (1993), que discutem a forma de medir a eficiência das universidades, verificando a robustez dos resultados a partir da utilização de diferentes especificações do modelo e alteração das variáveis utilizadas, Finlândia (El-Mahgary e Lahdelma, 1995), Portugal (Afonso e Santos, 2004), Canadá (Mcmillan e Datta, 1998) e Alemanha (Warning, 2004).

Por sua vez, Façanha e Marinho (1999) publicam o estudo sobre o ensino superior no Brasil, avaliando modelos de financiamento e incentivo à eficiência. Os autores analisam então o modelo alocativo utilizado pelo Ministério da Educação (MEC) para a distribuição de recursos públicos entre as instituições federais de ensino superior. Também utilizam a metodologia da análise envoltória de dados, levando à recomendação do reexame do modelo de alocação vigente e à implementação de mecanismos mais consistentes, com objetivos de avaliação permanente e de incentivo à gestão eficiente de recursos. Uma grande quantidade de trabalhos também foca as universidades públicas brasileiras, como Marinho, Resende e Façanha (1997), Belloni (2000), Costa et al. (2012) e Nuintin et al. (2014). O estudo de Alencastro e Fochezatto (2006), com enfoque na eficiência técnica na gestão de recursos das IES privadas, é exceção.

Com relação à análise de eficiência no ensino superior, a partir da comparação das instituiçóes públicas e privadas, podem-se citar os primeiros trabalhos na área de Rhodes e Southwick (1986), que encontram maior eficiência das IES privadas dos Estados Unidos, e Ahn, Charnes e Cooper (1988), que apontam para a maior eficiência das instituiçóes públicas daquele país. Mais recentemente, Çokgezen (2009) não encontra diferenças significativas entre as universidades públicas e privadas na Turquia para o curso de economia, quando considerada a qualidade dos outputs.

Osório, Mendes e Rabelo (1998) explicam que a ineficiência do setor público está ligada a alguns fatores. Um deles é o fato de que as organizaçóes públicas são pouco vulneráveis às forças de mercado, não sendo este um incentivador de práticas produtivas que levem à eficiência. $\mathrm{O}$ mercado fornece informaçóes ao setor produtivo, o que motiva o esforço em busca da eficiência. Essa motivação é a permanência da organização no mercado. A mesma lógica pode ser aplicada ao caso das instituiçóes de ensino, segundo Mancebón e Muñiz (2008). 
Desde o primeiro trabalho para o Brasil, de Façanha e Marinho (2001), estudos comparando a eficiência de IES públicas e privadas brasileiras apontam também para maior eficiência das instituiçôes privadas.

\subsection{A decomposição da eficiência no ensino}

A aplicação da análise envoltória de dados para medida da eficiência na área educacional é amplamente difundida. Porém, a maior parte dos trabalhos na área possui foco de avaliaçáo apenas no nível escolar, supondo assim que toda possível causa de ineficiência é decorrente da instituiçáo de ensino, ignorando-se a parcela de responsabilidade devida aos estudantes no processo. A avaliação única da eficiência com base nas IES não consegue captar possíveis variaçóes existentes dentro de uma mesma instituição, visto que diferentes níveis de eficiência se escondem atrás da eficiência média (Goldstein, 1997).

Nesse sentido, Thanassoulis e Portela (2002) utilizaram um novo critério de avaliação, a partir da metodologia DEA, que permite mensurar a participação de ambos os agentes no processo, ao decompor o nível de eficiência em dois componentes - um componente relativo à eficiência da instituição de ensino, e outro componente correspondente à eficiência e à motivação do estudante. A técnica utilizada foi também apresentada em Portela e Thanassoulis (2001), sendo a decomposição realizada entre diferentes tipos de instituiçóes de ensino (como as IES públicas e privadas). A ilustração desta metodologia pode ser visualizada na figura 1, adaptada de Sampaio e Guimarães (2009).

Suponha-se que A, B e C sejam diferentes IES; adicionalmente, A é uma IES pública, e $\mathrm{B}$ e $\mathrm{C}$ privadas. Dessa forma, as linhas contínuas representam as respectivas fronteiras de eficiência local $\left(\mathrm{EF}^{\mathrm{L}}\right)$ para cada uma das IES. Para dado aluno $Z$, estudante da instituição $\mathrm{C}$, sua eficiência em relação à IES em que estuda $\left(\mathrm{EF}_{1}\right)$ capta apenas o efeito de seu esforço e motivação, e será igual a 1, caso o estudante situe-se na fronteira de sua IES. Esta medida é dada então pela razão:

$$
E F_{1}=O Z / O Z^{1}
$$

A linha tracejada, por sua vez, descreve a fronteira de eficiência das IES de mesmo tipo $\left(\mathrm{EF}^{\mathrm{T}}\right)$. No exemplo ilustrado, é a fronteira máxima possível para os estudantes das instituiçóes privadas. Neste caso, situar-se na fronteira depende não apenas do desempenho do aluno, mas também da eficiência da IES quando comparada com as demais IES privadas. Para o aluno Z, seu coeficiente de eficiência em relação à $\mathrm{EF}^{\mathrm{T}}\left(\mathrm{EF}_{2}\right)$ será:

$$
E F_{2}=O Z / O Z^{2}
$$




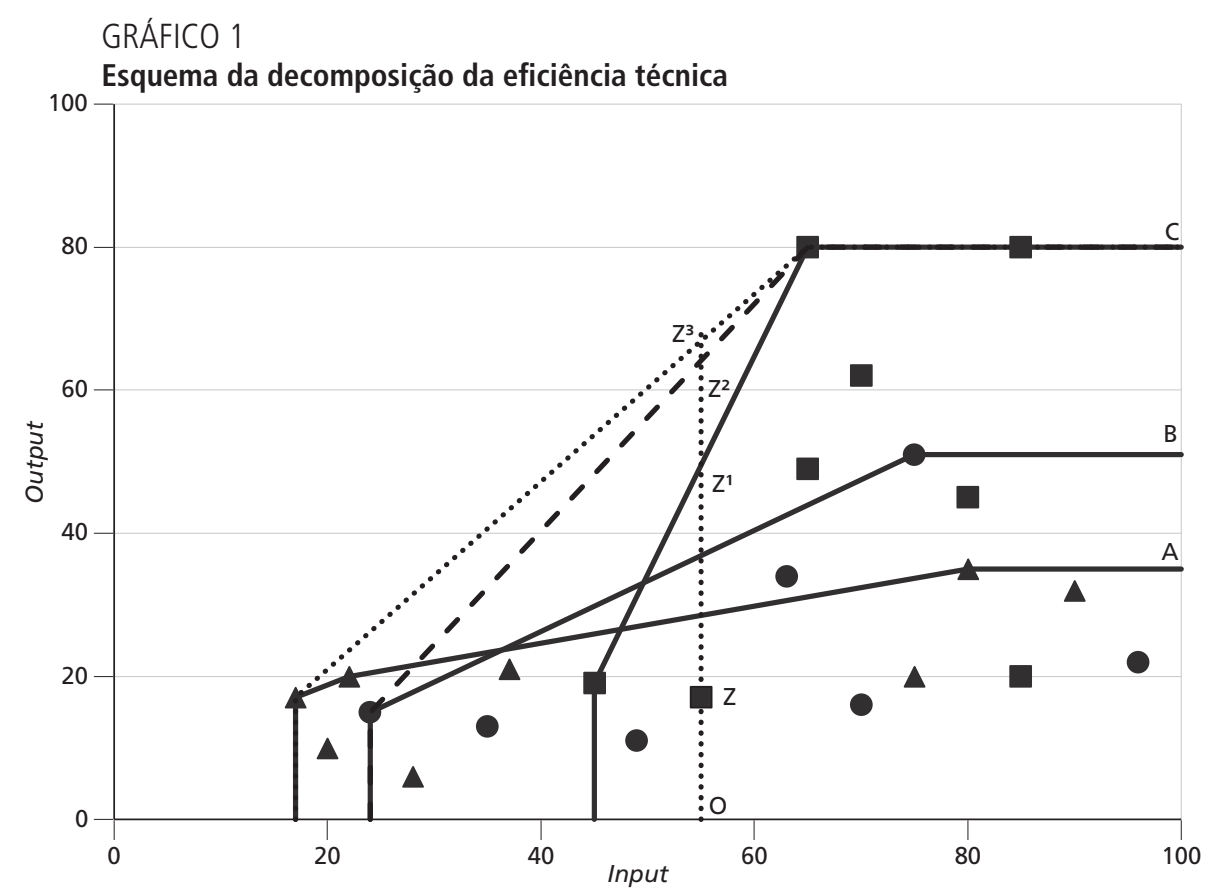

Fonte: Adaptado de Sampaio e Guimarães (2009).

Por fim, a linha pontilhada mostra a fronteira de eficiência global $\left(E F^{G}\right)$ formada por estudantes provenientes de todas as IES. Portanto, para um aluno situar-se nesta fronteira, é necessário que seu desempenho, o desempenho de sua instituiçáo e ainda o tipo de IES em que estuda sejam eficientes. A eficiência global do aluno $\mathrm{Z}\left(\mathrm{EF}_{3}\right)$ é entáo dada por:

$$
E F_{3}=O Z / O Z^{3}
$$

Alterando-se o foco de análise para as IES, observa-se que o segmento $Z^{1} Z^{2}$ representa a distância entre as fronteiras $\mathrm{EF}^{\mathrm{L}}$ e $\mathrm{EF}^{\mathrm{T}}$ da instituição $\mathrm{C}$, para o estudante $Z$. Seguindo a mesma linha de raciocínio, o segmento $Z^{1} Z^{3}$ retrata a distância existente entre as fronteiras $\mathrm{EF}^{\mathrm{L}}$ e $\mathrm{EF}^{\mathrm{G}}$. Desse modo, pode-se isolar a eficiência devida apenas às IES em relação às IES de mesmo tipo $\left(\mathrm{EF}_{4}\right)$ e também em relação a todas as instituiçóes $\left(\mathrm{EF}_{5}\right)$, da seguinte forma:

$$
\begin{aligned}
& E F_{4}=O Z^{1} / O Z^{2}=E F_{2} / E F_{1} \\
& E F_{5}=O Z^{1} / O Z^{3}=E F_{3} / E F_{1}
\end{aligned}
$$


É possível também encontrar a eficiência relativa ao tipo de instituição avaliada, com respeito aos demais tipos $\left(\mathrm{EF}_{6}\right)$ :

$$
E F_{6}=O Z^{2} / O Z^{3}=E F_{3} / E F_{2}
$$

\subsection{0 método Jackstrap}

Embora os modelos DEA venham sendo empregados com sucesso no estudo da administração pública e de organizaçóes sem fins lucrativos, por tratar-se de um modelo de fronteira determinística, a técnica é muito suscetível à presença de outliers e erros de medida (Peńa, 2008).

Visando contornar esta fragilidade, Stosic e Sousa (2003) propóem um método de detecção de outliers computacionalmente intensivo, mas independente da inspeção manual dos dados, denominada de Jackstrap. A técnica incorpora elementos dos métodos de Bootstrap e Jacknife, recorrendo ao cálculo do efeito da remoção de uma DMU sobre os scores de eficiência no restante da amostra (alavancagem). Formalmente, a alavancagem é definida como o desvio-padrão dos índices de eficiência antes e após a remoção de uma observação.

A aplicação do Jackstrap segue o seguinte algoritmo:

1) Seleciona-se aleatoriamente um subconjunto de $L$ DMUs. Os autores sugerem que $L$ contenha entre $10 \%$ e $20 \%$ do número total de $K$ DMUs. Calcula-se o índice de eficiência de cada DMU, considerando toda a subamostra e, posteriormente, retirando uma DMU de cada vez, recalculam-se os scores das $L-1$ observaçóes. Define-se então a alavancagem $\tilde{\ell}_{j}$ de cada DMU selecionada:

$$
\tilde{\ell}_{J}=\sqrt{\frac{\sum_{l=1, l \neq j}^{L}\left(\theta_{l j}^{*}-\theta_{l}\right)^{2}}{L-1}}
$$

Em que $\theta_{l j}^{*}$ corresponde ao score da DMU $l$ quando retirada a $j$-ésima DMU e $\theta_{l}$ é o score da DMU $l$, considerando-se toda a subamostra $L$.

2) Repete-se o passo 1 acima $B$ vezes, acumulando os valores das alavancagens obtidas nas diferentes subamostras aleatórias $\left(\tilde{\ell}_{j b}\right)$. B deve ser suficientemente grande para que cada DMU seja selecionada $n_{j}$ vezes (onde $n_{j} \approx B L / K$ ).

3) Calcula-se a alavancagem média para cada DMU:

$$
\tilde{\ell}_{k}=\frac{\sum_{b=1}^{n_{j}} \tilde{\ell}_{j b}}{n_{j}}
$$


4) Obtém-se a alavancagem média global:

$\tilde{\ell}=\frac{\sum_{k=1}^{K} \tilde{\ell}_{k}}{K}$

Entre as propostas apresentadas pelos autores para a detecção e tratamento dos outliers com base nas alavancagens calculadas, aquela que apresentou o melhor resultado na recuperação da distribuição dos índices de eficiência originais, após a inclusão de outliers em seus experimentos, foi a função heaviside, que define a seguinte regra de corte, levando em consideração o tamanho da amostra:

$$
P\left(\tilde{\ell}_{k}\right)=\left\{\begin{array}{l}
1, \tilde{\ell}_{k} \leq \tilde{\ell} \log K \\
0, \tilde{\ell}_{k}>\tilde{\ell} \log K
\end{array}\right.
$$

Sampaio de Sousa e Stosic (2005) consideram que a função heaviside providencia uma aproximação razoável do número de outliers.

\section{BASE DE DADOS E METODOLOGIA}

A base de dados utilizada em todo o trabalho consiste nos microdados do Enade de 2012 e 2015, referentes aos alunos concluintes em ciências econômicas, e podem ser encontrados na plataforma de microdados disponibilizada pelo Inep.

$\mathrm{O}$ desenvolvimento do trabalho é feito em duas etapas. Na primeira delas estima-se, por meio de mínimos quadrados ordinários (MQO), uma função relacionando à nota de formação específica obtida pelos alunos concluintes em ciências econômicas no Enade e suas respectivas características pessoais, demográficas e socioeconômicas. Rigorosamente, esta estimação deveria ser realizada utilizando-se dados transformados, para se garantir a obtenção de resultados dentro do intervalo observado das notas, limitado entre 0 e 100 . Porém, visto que o resultado obtido por meio das variáveis transformadas não difere muito daquele obtido por MQO, a utilização deste torna-se mais atrativa, devido à sua interpretação mais intuitiva (Guimarães e Sampaio, 2007).

O modelo de regressão linear fica definido da seguinte forma, com a descrição das variáveis apresentada no quadro 1 :

$$
\begin{aligned}
\text { Notaesp }= & \beta_{0}+\beta_{1} \text { Notager }+\beta_{2} \text { No }+\beta_{3} \text { Ne }+\beta_{4} \text { CO }+\beta_{5} \text { Sul }+\beta_{6} \text { Idade } \\
& +\beta_{7} \text { Mulher }+\beta_{8} \text { Moradia }_{1}+\beta_{9} \text { Moradia }_{2}+\beta_{10} \text { Negro } \\
& +\beta_{11} \text { Pardo }+\beta_{12} \text { Renda }_{1}+\beta_{13} \text { Renda }_{2}+\beta_{14} \text { Renda }_{3} \\
& +\beta_{15} \text { Renda }_{4}+\beta_{16} \text { Renda }_{5}+\beta_{17} \text { Renda }_{6}+\beta_{18} \text { Trab }_{1} \\
& +\beta_{19} \text { Trab }_{2}+\beta_{20} \text { Paissup }+\beta_{21} \text { Paismed }+\beta_{22} \text { Paisfund } \\
& +\beta_{23} \text { Medpriv }+\beta_{24} \text { Estudo }+\varepsilon
\end{aligned}
$$


Miranda et al. (2015) constataram, a partir de um levantamento de 52 artigos nacionais e internacionais sobre o desempenho acadêmico na área de negócios, que o conhecimento anteriormente acumulado do estudante foi a variável que apareceu com maior frequência entre os resultados significantes. Devido à ausência de dados relativos ao desempenho prévio dos alunos, a nota de formação geral foi utilizada como variável explicativa no modelo, levando-se em consideração que, por se tratar de questóes de cunho geral, a nota de formação geral está pouco associada ao conhecimento acumulado no ensino superior, segundo Moriconi e Nascimento (2014).

\section{QUADRO 1}

\section{Descrição das variáveis do modelo de regressão linear}

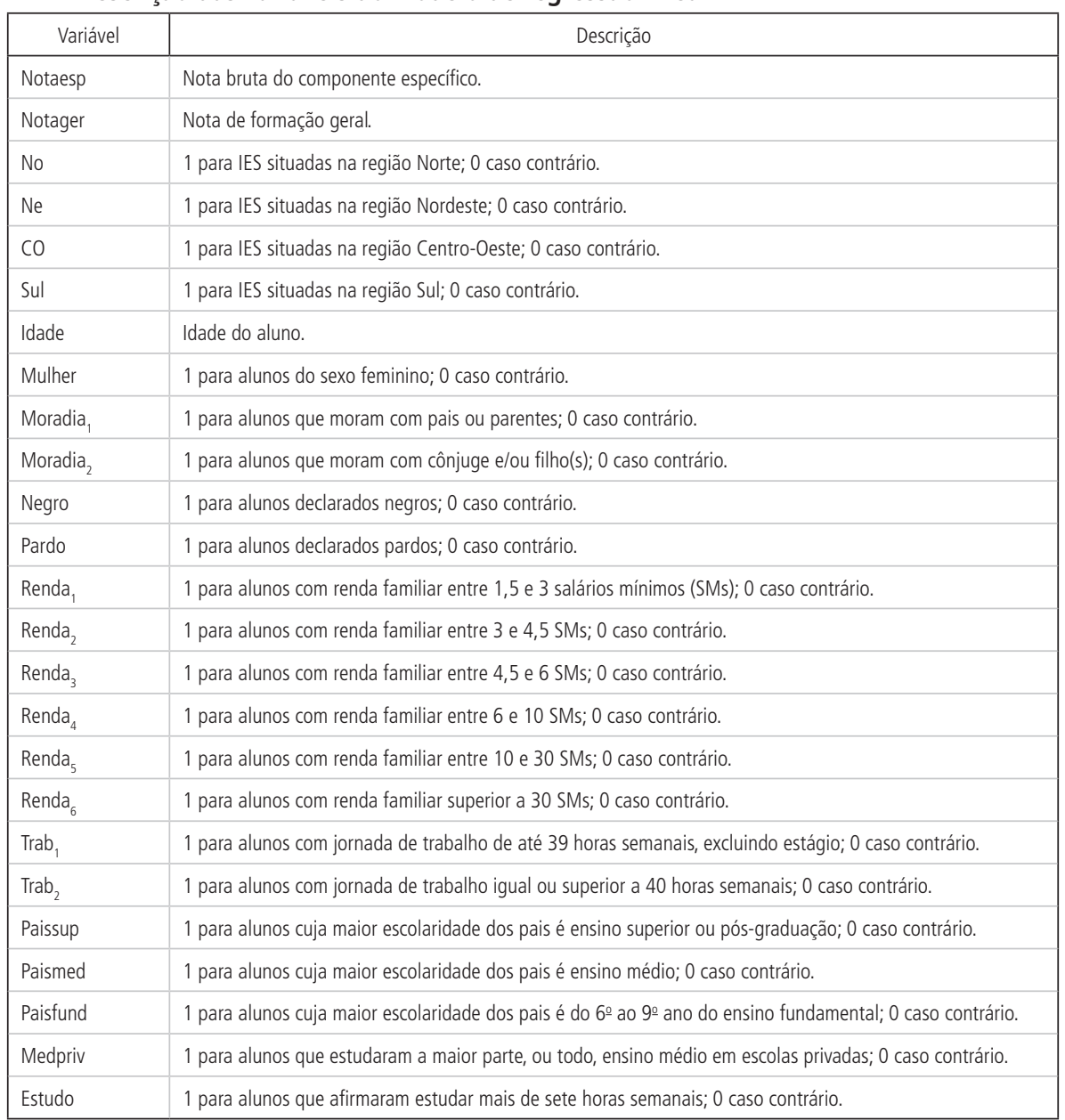


$\mathrm{Na}$ segunda etapa do trabalho, aplica-se a técnica de decomposição da eficiência técnica de Thanassoulis e Portela (2002), exposta na seção anterior, à base de dados. Como produto, emprega-se a nota bruta do componente específico (variável dependente da regressão estimada), considerada como proxy para o nível de conhecimento acadêmico adquirido pelos alunos ao final da graduação.

Entretanto, como apontam Sampaio e Guimarães (2009), este produto é um reflexo não apenas da qualidade e eficiência da IES, mas também envolve fatores pessoais e sociais, cognitivos e demográficos dos alunos. Portanto, para o controle destas variáveis, utilizam-se como insumo na análise os valores esperados da regressão estimada. Dessa forma, a eficiência de cada estudante e IES - será dada com base na comparação entre a nota potencial do aluno de acordo com seu background socioeconômico (nota esperada), e a nota de fato obtida por este aluno. $\mathrm{O}$ modelo utilizado no trabalho é equivalente ao DEA-BCC apresentado na equação (5), que supõe retornos variáveis de escala e orientação a produto.

Após o cálculo da regressão e antes de se proceder à análise envoltória de dados, emprega-se a técnica de Jackstrap para identificação de outliers, descrito na seção anterior, a partir do DEA com retornos variáveis de escala e orientação ao produto, considerando-se o índice de eficiência 3 definido anteriormente (EF3). Como ponto de corte, considera-se a função heaviside.

Ao longo do trabalho, serão considerados apenas alunos com resultados válidos na prova e que responderam a todas as questóes necessárias do questionário socioeconômico. Foram desconsiderados também alunos com nota zero na parte de formação geral ou de componente específico da prova, desconsiderando-se, assim, alunos que estavam presentes na prova, mas não se motivaram a responder a ela. Devido à sua baixa representatividade na amostra, optou-se por não considerar alunos indígenas. Além disso, buscando obter fronteiras de eficiência locais mais robustas, foram considerados apenas alunos cujas IES possuíam ao menos 25 alunos concluintes realizando o Enade.

Ao final do processo de seleção e tratamento de dados, restaram, em 2012, 6.915 alunos e 102 instituiçóes, distribuídos entre 54 IES públicas (com 3.972 alunos) e 48 IES privadas (totalizando 2.943 alunos). Dessa forma, realizam-se 105 procedimentos DEA distintos (um para cada fronteira local, mais duas fronteiras para as categorias administrativas e uma fronteira global). Por seu turno, para 2015, houve um total de 6.880 alunos e 99 instituiçôes, sendo 60 delas públicas (somando 4.519 alunos) e 39 privadas (2.361 alunos); para esse ano, são realizados, portanto, 102 DEA. 


\section{RESULTADOS}

\subsection{Análise descritiva dos dados}

O perfil completo dos alunos concluintes em ciências econômicas em 2012 e 2015 empregados no trabalho é apresentado na tabela 1. O perfil predominante de alunos, em ambos os anos, é de estudantes residentes no Sudeste, especialmente entre as IES privadas, sendo a predominância de alunos na região de quase $70 \%$. Aproximadamente $60 \%$ dos alunos também são homens, nos quatro diferentes coortes. A quantidade de alunos de raça branca ou amarela também é superior a $60 \%$ em todas as amostras. Igualmente, a quantidade de alunos que residem com os pais varia no intervalo de aproximadamente $60 \%$ a $70 \%$ do total de estudantes. Com relação à renda, as faixas de rendimento familiar que concentram o maior número de estudantes estão entre 6 e $30 \mathrm{SMs}$, embora, entre os alunos de instituiçóes privadas, a quantidade de alunos com renda superior a $30 \mathrm{SMs}$ seja acima de $10 \%$ em ambos os anos.

TABELA 1

Alunos concluintes em ciências econômicas no Brasil (2012 e 2015)

\begin{tabular}{|c|c|c|c|c|c|c|c|c|}
\hline \multirow{3}{*}{$\begin{array}{l}\text { Variáveis } \\
\text { Variáveis contínuas }\end{array}$} & \multicolumn{4}{|c|}{2012} & \multicolumn{4}{|c|}{2015} \\
\hline & \multicolumn{2}{|c|}{ Público (3.972) } & \multicolumn{2}{|c|}{ Privado (2.943) } & \multicolumn{2}{|c|}{ Público (4.519) } & \multicolumn{2}{|c|}{ Privado (2.361) } \\
\hline & Média & $\begin{array}{l}\text { Desvio- } \\
\text {-padrão }\end{array}$ & Média & $\begin{array}{l}\text { Desvio- } \\
\text {-padrão }\end{array}$ & Média & $\begin{array}{l}\text { Desvio- } \\
\text {-padrão }\end{array}$ & Média & $\begin{array}{l}\text { Desvio- } \\
\text {-padrão }\end{array}$ \\
\hline Nota do componente específico & 28,73 & 12,51 & 27,84 & 12,00 & 36,88 & 14,84 & 37,46 & 15,29 \\
\hline \multicolumn{9}{|l|}{ Variáveis independentes } \\
\hline Nota de formação geral & 45,58 & 16,33 & 44,77 & 16,80 & 59,52 & 16,50 & 58,12 & 16,20 \\
\hline Idade & 26 & 5,09 & 25 & 5,35 & 26 & 5,24 & 25 & 5,14 \\
\hline Variáveis dummy & Soma & $\%$ & Soma & $\%$ & Soma & $\%$ & Soma & $\%$ \\
\hline \multicolumn{9}{|l|}{ Região } \\
\hline Norte & 72 & 1,81 & 34 & 1,16 & 438 & 9,69 & 30 & 1,27 \\
\hline Nordeste & 1.283 & 32,30 & 173 & 5,88 & 1.081 & 23,92 & 163 & 6,90 \\
\hline Centro-Oeste & 292 & 7,35 & 119 & 4,04 & 372 & 8,23 & 79 & 3,35 \\
\hline Sul & 1.011 & 25,45 & 590 & 20,05 & 953 & 21,09 & 467 & 19,78 \\
\hline Sudeste & 1.314 & 33,08 & 2.027 & 68,88 & 1.675 & 37,07 & 1.622 & 68,70 \\
\hline \multicolumn{9}{|l|}{ Sexo } \\
\hline Mulheres & 1.673 & 42,12 & 1.189 & 40,40 & 1.948 & 43,11 & 899 & 38,08 \\
\hline Homens & 2.299 & 57,88 & 1.754 & 59,60 & 2.571 & 56,89 & 1.462 & 61,92 \\
\hline
\end{tabular}


(Continuação)

\begin{tabular}{|c|c|c|c|c|c|c|c|c|}
\hline \multirow{2}{*}{ Variáveis } & \multicolumn{4}{|c|}{2012} & \multicolumn{4}{|c|}{2015} \\
\hline & \multicolumn{2}{|c|}{ Público (3.972) } & \multicolumn{2}{|c|}{ Privado (2.943) } & \multicolumn{2}{|c|}{ Público (4.519) } & \multicolumn{2}{|c|}{ Privado (2.361) } \\
\hline \multicolumn{9}{|l|}{ Cor } \\
\hline Negro & 216 & 5,44 & 121 & 4,11 & 318 & 7,04 & 111 & 4,70 \\
\hline Pardo & 1.152 & 29,00 & 455 & 15,46 & 1.329 & 29,41 & 433 & 18,34 \\
\hline Branco ou amarelo & 2.604 & 65,56 & 2.367 & 80,43 & 2.872 & 63,55 & 1.817 & 76,96 \\
\hline \multicolumn{9}{|l|}{ Moradia } \\
\hline País/parentes & 2.530 & 63,70 & 2.140 & 72,71 & 2.700 & 59,75 & 1.686 & 71,41 \\
\hline Cônjuge e/ou filho(s) & 639 & 16,09 & 424 & 14,41 & 789 & 17,46 & 323 & 13,68 \\
\hline Sozinho/outros & 803 & 20,22 & 379 & 12,88 & 1.030 & 22,79 & 352 & 14,91 \\
\hline \multicolumn{9}{|l|}{ Renda familiar } \\
\hline Até 1,5 SM & 394 & 9,92 & 119 & 4,04 & 390 & 8,63 & 81 & 3,43 \\
\hline 1,5 SM a 3 SMs & 693 & 17,45 & 314 & 10,67 & 810 & 17,92 & 260 & 11,01 \\
\hline $3 \mathrm{SMs}$ a $4,5 \mathrm{SMs}$ & 663 & 16,69 & 436 & 14,81 & 793 & 17,55 & 315 & 13,34 \\
\hline $4,5 \mathrm{SMs}$ a $6 \mathrm{SMs}$ & 545 & 13,72 & 381 & 12,95 & 597 & 13,21 & 285 & 12,07 \\
\hline 6 SMs a 10 SMs & 768 & 19,34 & 661 & 22,46 & 839 & 18,57 & 471 & 19,95 \\
\hline $10 \mathrm{SMs}$ a $30 \mathrm{SMs}$ & 755 & 19,01 & 697 & 23,68 & 882 & 19,52 & 604 & 25,58 \\
\hline Acima de 30 SMs & 154 & 3,88 & 335 & 11,38 & 208 & 4,60 & 345 & 14,61 \\
\hline \multicolumn{9}{|l|}{ Trabalho } \\
\hline Não trabalha & 1.449 & 36,48 & 757 & 25,72 & 1.741 & 38,53 & 635 & 26,90 \\
\hline Trabalho até 39 horas semanais & 1.015 & 25,55 & 666 & 22,63 & 1.094 & 24,21 & 579 & 24,52 \\
\hline $\begin{array}{l}\text { Trabalho acima de } 40 \text { horas } \\
\text { semanais }\end{array}$ & 1.508 & 37,97 & 1.520 & 51,65 & 1.684 & 37,26 & 1.147 & 48,58 \\
\hline \multicolumn{9}{|l|}{ Educação dos pais } \\
\hline Até $05^{\circ}$ ano & 478 & 12,03 & 343 & 11,65 & 555 & 12,28 & 188 & 7,96 \\
\hline Até o 9o ano & 372 & 9,37 & 267 & 9,07 & 407 & 9,01 & 223 & 9,45 \\
\hline Ensino médio & 1.285 & 32,35 & 886 & 30,11 & 1.545 & 34,19 & 709 & 30,03 \\
\hline Superior/pós-graduação & 1.837 & 46,25 & 1.447 & 49,17 & 2.012 & 44,52 & 1.241 & 52,56 \\
\hline \multicolumn{9}{|l|}{ Educação/estudos } \\
\hline Ensino médio público & 1.829 & 46,05 & 1.439 & 48,90 & 2.314 & 51,21 & 1.051 & 44,52 \\
\hline Ensino médio privado & 2.143 & 53,95 & 1.504 & 51,10 & 2.205 & 48,79 & 1.310 & 55,48 \\
\hline Estuda até 7 horas semanais & 3.224 & 81,17 & 2.515 & 85,46 & 3.549 & 78,54 & 1.842 & 78,02 \\
\hline Estuda mais de 7 horas & 748 & 18,83 & 428 & 14,54 & 970 & 21,46 & 519 & 21,98 \\
\hline
\end{tabular}


Enquanto entre as IES públicas o número de alunos que não trabalham é semelhante ao número de alunos que trabalham em jornadas de 40 horas semanais ou mais, no caso das IES privadas, o número de alunos empregados em jornadas de trabalho integral representa a maior parte da amostra.

Considerando-se a educação dos pais, o perfil predominante é de alunos que têm ao menos um dos pais com ensino superior ou pós-graduação; por sua vez, em relação ao estudo dos próprios alunos, há um equilíbrio entre alunos que realizaram a maior parte do ensino médio em colégios públicos ou privados, enquanto aproximadamente $80 \%$ de todos os alunos afirmaram estudar menos de sete horas semanais.

Avaliando-se o desempenho dos estudantes no Enade, com base na nota do componente específico, observa-se um resultado semelhante entre alunos de instituiçôes públicas e privadas, sendo a nota média ligeiramente superior entre alunos de IES públicas, em 2012, e entre alunos de IES privadas em 2015. O maior detalhamento da nota é apresentado nos gráficos 2 e 3, que contêm a distribuição de notas das instituiçóes públicas e privadas para 2012 e 2015, respectivamente. Além disso, para ambas as categorias administrativas, a nota média foi substancialmente superior em 2015.

GRÁFICO 2

Distribuição de notas das instituições públicas e privadas no Enade 2012

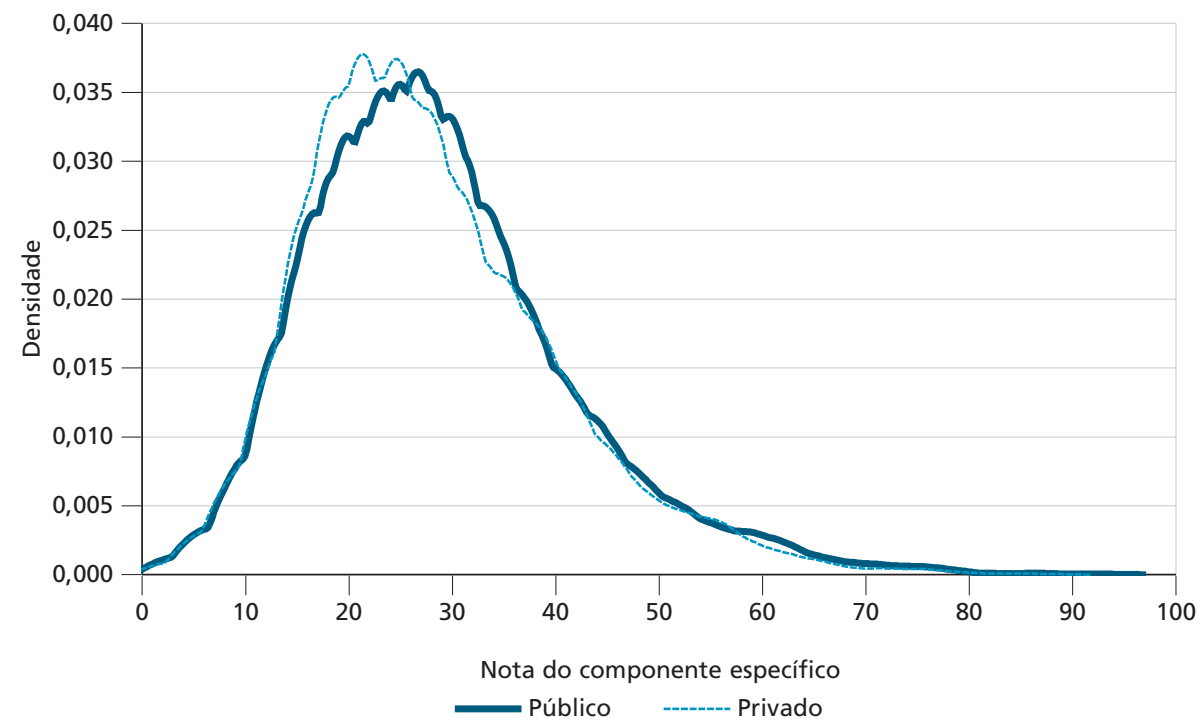

Elaboração dos autores. 


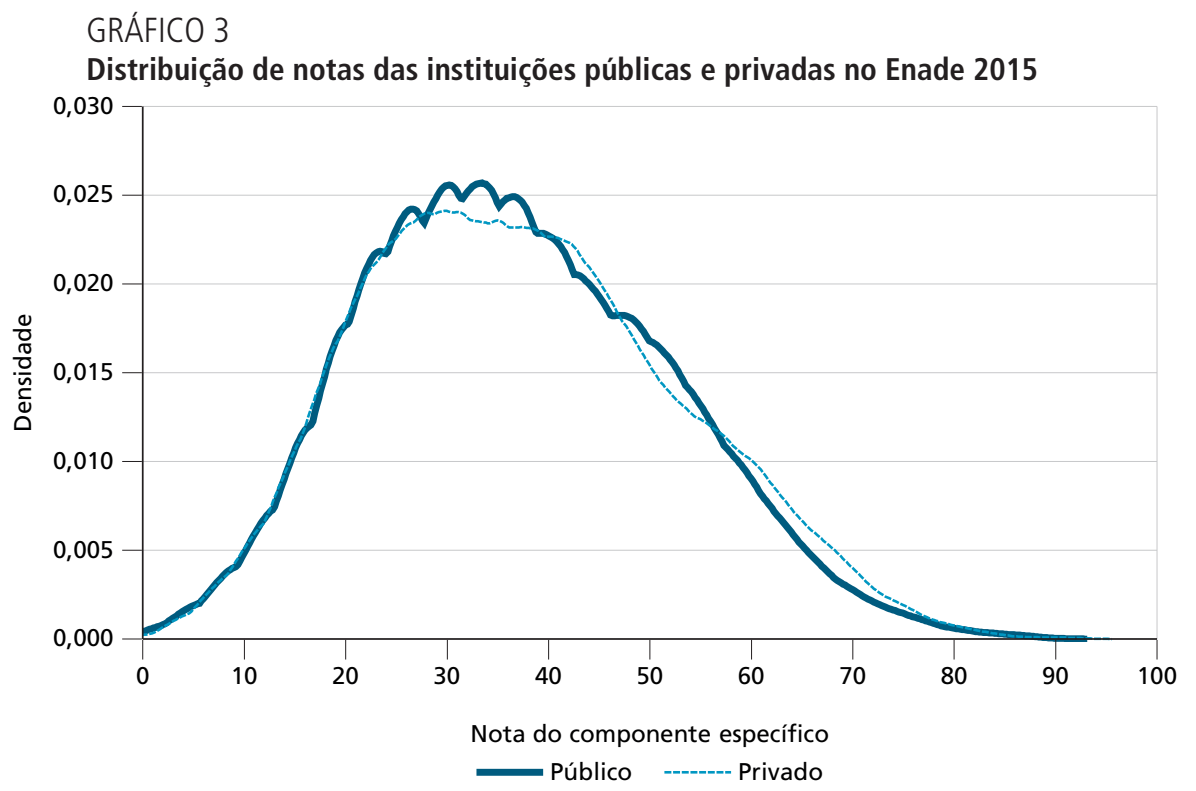

Elaboração dos autores.

\subsection{Modelo de regressão linear}

Os resultados do modelo de regressão linear para ambos os anos são apresentados na tabela 2, juntamente com o erro-padrão robusto dos parâmetros. Destaca-se que os resultados mantêm a consistência entre os anos analisados, levando-se em consideração que nenhuma das variáveis apresentou alteração significativa de sinal entre 2012 e 2015.

TABELA 2

Regressão linear: alunos concluintes em economia (2012 e 2015)

\begin{tabular}{lcccc}
\hline \multirow{2}{*}{ Variável } & \multicolumn{2}{c}{2012} & \multicolumn{2}{c}{2015} \\
\cline { 2 - 5 } & Coeficiente & Erro-padrão robusto & Coeficiente & Erro-padrão robusto \\
\hline Nota de formação geral & $0,24799^{*}$ & 0,00822 & $0,30799^{*}$ & 0,00966 \\
Norte & $-1,89176^{* *}$ & 0,92524 & $-5,44701^{*}$ & 0,59770 \\
Nordeste & $-1,82671^{*}$ & 0,35532 & $-4,02404^{*}$ & 0,45019 \\
Centro-Oeste & $-1,07346^{* * *}$ & 0,64903 & $-1,23593^{* * *}$ & 0,67722 \\
Sul & $-0,80537^{* *}$ & 0,34269 & $-0,71157^{* * *}$ & 0,43023 \\
Idade & $-0,07306^{* *}$ & 0,02864 & $-0,20492^{*}$ & 0,03398 \\
Mulher & $-3,33187^{*}$ & 0,26635 & $-4,60010^{*}$ & 0,31775 \\
Pais/parentes & $-1,96280^{*}$ & 0,40127 & $-0,87047^{* *}$ & 0,40895 \\
Cônjuge e/ou filho(s) & $-1,86815^{*}$ & 0,48958 & $-0,39265$ & 0,55496 \\
Negro & $-0,91304$ & 0,56724 & $-1,39513^{* *}$ & 0,63198 \\
\hline
\end{tabular}




\begin{tabular}{|c|c|c|c|c|}
\hline \multirow{2}{*}{ Variável } & \multicolumn{2}{|c|}{2012} & \multicolumn{2}{|c|}{2015} \\
\hline & Coeficiente & Erro-padrão robusto & Coeficiente & Erro-padrão robusto \\
\hline Pardo & 0,16286 & 0,33818 & $-0,48883$ & 0,37459 \\
\hline $1,5 \mathrm{SM}$ a $3 \mathrm{SMs}$ & 0,18837 & 0,58608 & $1,71889^{* *}$ & 0,67059 \\
\hline 3 SMs a 4,5 SMs & $1,32457^{* *}$ & 0,58892 & $2,57263^{*}$ & 0,68864 \\
\hline $4,5 \mathrm{SMs}$ a $6 \mathrm{SMs}$ & $1,53882^{* *}$ & 0,61586 & $3,32027^{*}$ & 0,74539 \\
\hline 6 SMs a 10 SMs & $2,20008^{*}$ & 0,60084 & $4,85819^{*}$ & 0,72697 \\
\hline 10 SMs a 30 SMs & $3,36707^{*}$ & 0,64000 & $6,67945^{*}$ & 0,77209 \\
\hline Acima de 30 SMs & $4,56905^{*}$ & 0,84662 & $7,60820^{*}$ & 0,95171 \\
\hline Trabalho até 39 horas & $-1,93372^{*}$ & 0,38022 & $-1,75304^{*}$ & 0,41852 \\
\hline Trabalho acima de 40 horas & $-3,10397^{*}$ & 0,33373 & $-3,69445^{*}$ & 0,38177 \\
\hline Pais com ensino superior & $0,98816^{* *}$ & 0,47144 & $1,30336^{* *}$ & 0,57994 \\
\hline Pais com ensino médio & 0,10329 & 0,42507 & $1,08398^{* *}$ & 0,52424 \\
\hline Pais até o 9o ano & $-0,10939$ & 0,50757 & 0,68232 & 0,63144 \\
\hline Ensino médio privado & $0,75770^{* *}$ & 0,32012 & 0,04329 & 0,38355 \\
\hline Estuda mais de 7 horas & $3,44180^{*}$ & 0,39495 & $3,29034^{*}$ & 0,38432 \\
\hline Constante & $21,08814^{*}$ & 1,09751 & $24,31634^{*}$ & 1,36529 \\
\hline Observações & \multicolumn{2}{|c|}{6.915} & \multicolumn{2}{|c|}{6.880} \\
\hline$F$ & \multicolumn{2}{|c|}{64,19} & \multicolumn{2}{|c|}{117,72} \\
\hline$R^{2}$ & \multicolumn{2}{|c|}{0,2141} & \multicolumn{2}{|c|}{0,2780} \\
\hline
\end{tabular}

Elaboração dos autores.

Obs.: * $p<0,01 ;{ }^{* *} p<0,05 ;{ }^{* * *} p<0,1$.

Ratificando as observaçôes de Miranda et al. (2015) acerca da importância do conhecimento prévio do aluno como importante previsor do desempenho do aluno no ensino superior, a nota de formação geral apresenta, em ambos os anos, resultado positivo e significativo ao nível de confiança de 99\%. Cada ponto extra na nota de formação geral do aluno representa, em média, um incremento de 0,25 a 0,3 na nota do componente específico.

A região geográfica do aluno também assume importância, levando-se em consideração que, em comparação com alunos do Sudeste, estudantes de todas as demais regiōes apresentam desempenho inferior, ao nível de significância mínimo de $10 \%$, em ambos os anos, mantendo-se constantes os demais fatores da análise. Os alunos da região Norte são os que apresentam o desempenho mais baixo, seguidos dos alunos do Nordeste, Centro-Oeste e Sul. Idade e gênero também são dois fatores significativos, sendo que alunos mais velhos e do sexo feminino apresentam desempenho médio inferior.

Em relação à moradia do estudante, o desempenho daqueles que moram com os pais ou parentes também é inferior, comparado aos alunos que moram sozinhos, ou têm outros tipos de moradia. A performance de alunos que moram com cônjuge 
e/ou filhos só apresenta significância estatística em 2012. Por seu turno, a cor é um fator determinante da nota dos discentes apenas em 2015, no qual alunos negros possuem desempenho, em média, inferior em relação a alunos brancos ou amarelos, considerando-se os demais fatores constantes. Alunos pardos, por sua vez, não possuem diferenças significativas de resultado.

Avaliando-se a renda familiar dos estudantes, e comparando-a com alunos com renda de no máximo 1,5 SM, observa-se que, com exceção da faixa de renda de 1,5 a $3 \mathrm{SMs}$ em 2012, todas as demais faixas possuem efeito positivo na determinação da nota dos alunos, ao nível de significância mínimo de 5\%. Ademais, o efeito incremental das faixas de renda é monotonicamente superior ao efeito da faixa anterior. Por sua vez, tanto em 2012 quanto em 2015, o fato de o aluno trabalhar é prejudicial para seu desempenho, especialmente entre alunos que trabalham em período integral.

Não foram encontradas diferenças significativas em alunos cuja educação máxima dos pais situa-se entre o 6ㅇ e o 9o do ensino fundamental, em comparaçáo com o desempenho de estudantes cujos pais estudaram até, no máximo, o 5 o ano de ensino fundamental. A diferença é, no entanto, significativa no caso de ao menos um dos pais ingressarem no ensino médio, para a amostra de 2015. No que concerne à influência da educação dos pais, é positiva e significante em ambos os anos, quando considerado o efeito do ensino superior ou pós-graduação.

Por fim, analisando-se a educação dos próprios alunos, o ensino médio realizado em sua maior parte em instituiçóes privadas apresenta um efeito significativo apenas em 2012; e o costume de estudar sete horas ou mais por semana é um fator positivo e significativo para o desempenho estudantil em 2012 e 2015.

\subsection{Detecção de outliers}

Após a estimação do modelo de regressão linear e a obtenção das notas esperadas dos alunos, procede-se à deteç̧ão de outliers, com base na técnica de Jackstrap. Em ambos os anos, foram utilizadas subamostras de setecentos alunos, e 2 mil replicaçôes, com base no nível de eficiência 3, que considera a fronteira de eficiência global dos alunos, levando em conta retornos variáveis de escala e orientação ao produto.

Para 2012, com os parâmetros definidos acima e 6.915 alunos, cada amostra foi selecionada, em média, 202,35 vezes. A alavancagem média foi calculada em $7,39 \times 10^{-5}$. Seguindo-se a regra definida pela função heaviside, o ponto de corte foi definido em $\tilde{\ell}_{k}=0,00028$. Assim, foram detectados e retirados do restante da análise 109 DMUs. A influência destas observações na determinação da fronteira de eficiência pode ser observada no gráfico 4, que apresenta o histograma da eficiência 3 antes e após a remoçáo destas DMUs, verificando-se o aumento generalizado da eficiência. 


\section{GRÁFICO 4}

Histograma de eficiência antes e após remoção de outliers (2012)

$4 \mathrm{~A}$ - EF3 com outliers

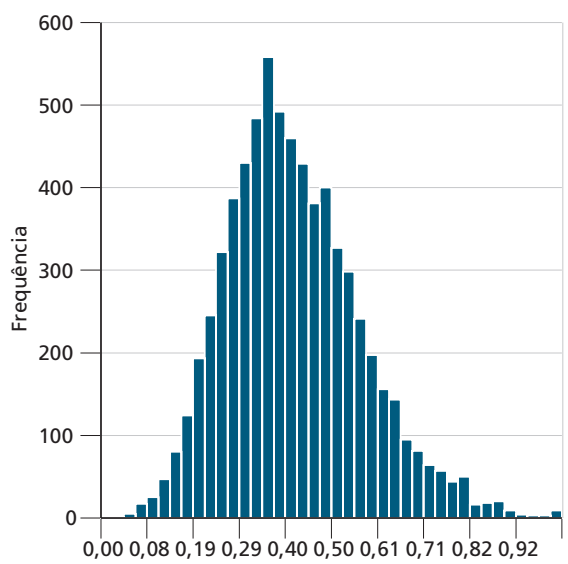

(a) EF3 com outliers
$4 \mathrm{~B}$ - EF3 sem outliers

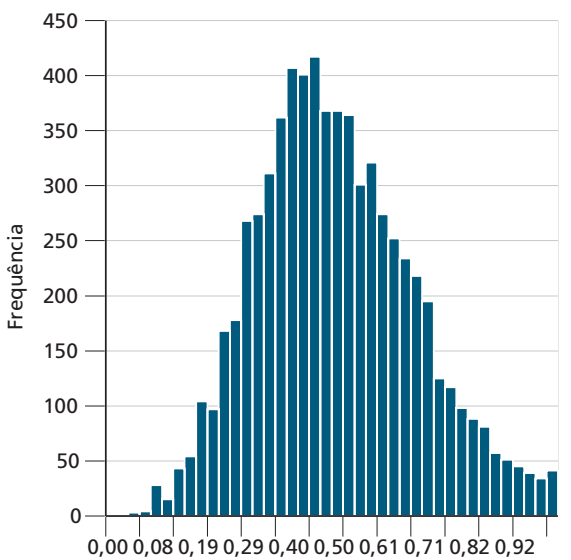

(b) EF3 sem outliers

Elaboração dos autores.

$\mathrm{Na}$ análise de 2015, que contava inicialmente com 6.880 alunos, cada amostra foi selecionada, em média, 203,39 vezes, com alavancagem média calculada em 7,7×10-5. A função heaviside define o ponto de corte em $\tilde{\ell}_{k}=0,00029$. Dessa forma, para 2015, 107 observaçóes foram consideradas outliers e removidas do restante do estudo. A influência destas observações também é apresentada no gráfico 5, que demonstra um incremento sensível na eficiência média da amostra após a remoção das DMUs de maior alavancagem.

GRÁFICO 5

Histograma de eficiência antes e após remoção de outliers (2015)

$5 \mathrm{~A}$ - EF3 com outliers

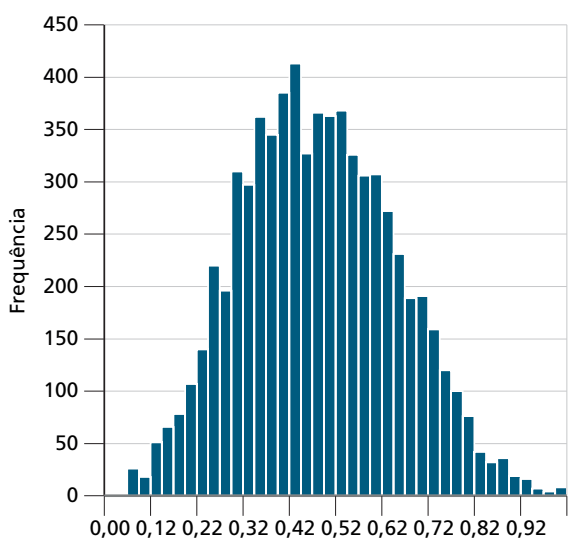

(a) EF3 com outliers

\section{$5 B$ - EF3 sem outliers}

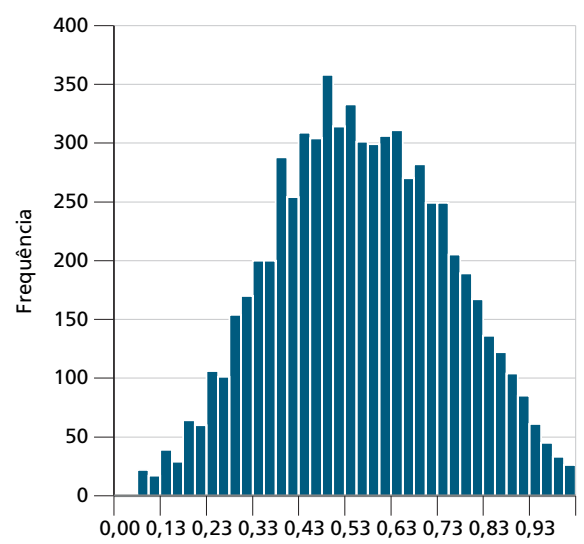

(b) EF3 sem outliers

Elaboração dos autores. 
Após a remoção das DMUs de maior influência, as instituiçóes Universidade Estadual de Mato Grosso do Sul e Universidade de Salvador passaram a contar com 24 alunos em 2012, enquanto a Escola de Economia de Sáo Paulo possuía 23 alunos em 2015. Considerando-se esta quantidade de alunos apenas marginalmente inferior ao limite mínimo definido de 25 alunos, optou-se por manter as instituiçôes na análise.

\subsection{Análise envoltória de dados}

Dando sequência ao estudo, foram calculados os índices de eficiências referentes às fronteiras locais (EF1), por categoria administrativa (EF2), e a fronteira global (EF3) dos alunos concluintes em ciências econômicas para os anos de $2012 \mathrm{e}$ 2015 que se mantiveram na amostra após a exclusão dos outliers. Tal como no Jacktrap, nesta etapa também se considera o DEA com retornos variáveis de escala e orientação ao produto. Com base nestes índices, pôde-se também calcular os índices de eficiência relativos às IES, por meio da decomposição da eficiência. A representação das fronteiras de eficiência construídas a partir das notas esperadas e observadas dos alunos, para ambos os anos, é apresentada nos apêndices A e B.

A tabela 3 mostra o ranking das vinte IES mais eficientes, ordenadas segundo a média geométrica do índice de eficiência 5 das instituiçôes. $\mathrm{O}$ uso da média geométrica é justificado por possibilitar a desagregação também da média dos índices de eficiência, não apenas os índices individuais. Dessa forma, a média do índice de eficiência 3 das IES ( $\overline{\mathrm{EF} 3}$ ) pode ser calculado como o produto da eficiência média dos alunos pela eficiência média das IES ( $\overline{\mathrm{EF} 3}=\mathrm{EF} 1 \mathrm{x}$ EF5). No restante do trabalho, qualquer menção a valores médios refere-se à média geométrica.

TABELA 3

Ranking de eficiência das IES em economia (2012 e 2015)

\begin{tabular}{|c|c|c|c|c|c|c|c|c|c|}
\hline \multicolumn{5}{|c|}{2012} & \multicolumn{5}{|c|}{2015} \\
\hline IES & Categoria & EF1 & EF3 & EF5 & IES & Categoria & EF1 & EF3 & EF5 \\
\hline UFRGS & Pública & 0,532 & 0,523 & 0,983 & Ibmec/RJ & Privada & 0,584 & 0,573 & 0,982 \\
\hline UnB & Pública & 0,728 & 0,697 & 0,958 & UFRGS & Pública & 0,637 & 0,623 & 0,978 \\
\hline UFF & Pública & 0,494 & 0,472 & 0,956 & UFRJ & Pública & 0,626 & 0,607 & 0,969 \\
\hline UFMG & Pública & 0,629 & 0,601 & 0,956 & UFPA & Pública & 0,525 & 0,501 & 0,956 \\
\hline UFC & Pública & 0,484 & 0,461 & 0,951 & UnB & Pública & 0,687 & 0,656 & 0,956 \\
\hline Udesc & Pública & 0,574 & 0,543 & 0,946 & Ibmec/MG & Privada & 0,691 & 0,661 & 0,956 \\
\hline EESP & Privada & 0,717 & 0,674 & 0,940 & Unicamp & Pública & 0,625 & 0,597 & 0,955 \\
\hline PUC-SP & Privada & 0,455 & 0,427 & 0,937 & UFPR & Pública & 0,600 & 0,571 & 0,951 \\
\hline Mackenzie & Privada & 0,501 & 0,468 & 0,934 & PUC-Rio & Privada & 0,550 & 0,522 & 0,950 \\
\hline UFPI & Pública & 0,449 & 0,418 & 0,932 & FGV EBEF & Privada & 0,870 & 0,821 & 0,944 \\
\hline
\end{tabular}


(Continuação)

\begin{tabular}{|c|c|c|c|c|c|c|c|c|c|}
\hline \multicolumn{5}{|c|}{2012} & \multicolumn{5}{|c|}{2015} \\
\hline IES & Categoria & EF1 & EF3 & EF5 & IES & Categoria & EF1 & EF3 & EF5 \\
\hline FGV EBEF & Privada & 0,557 & 0,516 & 0,925 & Insper & Privada & 0,670 & 0,632 & 0,943 \\
\hline Insper & Privada & 0,529 & 0,489 & 0,925 & UFPE & Pública & 0,562 & 0,530 & 0,942 \\
\hline UFPE & Pública & 0,544 & 0,502 & 0,923 & Fecap & Privada & 0,727 & 0,682 & 0,938 \\
\hline UFPR & Pública & 0,517 & 0,476 & 0,920 & UFSC & Pública & 0,523 & 0,484 & 0,925 \\
\hline UFV & Pública & 0,546 & 0,501 & 0,918 & UFRRJ & Pública & 0,517 & 0,477 & 0,922 \\
\hline Uesb & Pública & 0,453 & 0,414 & 0,913 & UFRR & Pública & 0,505 & 0,461 & 0,914 \\
\hline UFBA & Pública & 0,523 & 0,477 & 0,913 & UFABC & Pública & 0,705 & 0,644 & 0,914 \\
\hline Ibmec/RJ & Privada & 0,568 & 0,513 & 0,904 & Ufam & Pública & 0,524 & 0,475 & 0,906 \\
\hline UFPB & Pública & 0,575 & 0,519 & 0,902 & UFU & Pública & 0,603 & 0,545 & 0,904 \\
\hline Unicamp & Pública & 0,647 & 0,581 & 0,898 & Unifesp & Pública & 0,657 & 0,593 & 0,903 \\
\hline
\end{tabular}

Elaboração dos autores.

Obs.: UFRGS - Universidade Federal do Rio Grande do Sul; UnB - Universidade de Brasília; UFF - Universidade Federal Fluminense; UFMG - Universidade Federal de Minas Gerais; UFC - Universidade Federal do Ceará; Udesc - Universidade do Estado de Santa Catarina; EESP - Escola de Economia de São Paulo da Fundação Getulio Vargas; PUC-SP - Pontifícia universidade Católica de São Paulo; UFPI - Universidade Federal do Piauí; FGV EBEF - Escola Brasileira de Economia e Finanças; UFPE - Universidade Federal de Pernambuco; UFPR - Universidade Federal do Paraná; UFV - Universidade Federal de Viçosa; Uesb - Universidade Estadual do Sudoeste da Bahia; UFBA - Universidade Federal da Bahia; UFPB - Universidade Federal da Paraíba; Unicamp - Universidade Estadual de Campinas; UFRJ - Universidade Federal do Rio de Janeiro; UFPA Universidade Federal do Pará; PUC-Rio - Pontifícia Universidade Católica do Rio de Janeiro; Fecap - Fundação Escola de Comércio Álvares Penteado; UFSC - Universidade Federal de Santa Catarina; UFRRJ - Universidade Federal Rural do Rio de Janeiro; UFRR - Universidade Federal de Roraima; UFABC - Universidade Federal do ABC; Ufam - Universidade Federal do Amazonas; UFU - Universidade Federal de Uberlândia; Unifesp - Universidade Federal de São Paulo.

Tanto em 2012 quanto em 2015, o ranking é composto de catorze IES públicas e seis IES privadas. Ademais, oito instituições estão presentes em ambos os anos: Ibmec-RJ, UFRGS, UnB, UFPR, FGV EBEF, Insper, UFPE e Unicamp. Apesar do predomínio das IES públicas no ranking, ao se estenderem os resultados para o conjunto de todas as IES, as diferenças de resultado são pequenas. A eficiência média das instituiçóes públicas é de 0,811, enquanto a média das instituiçóes privadas é de 0,790 , para 2012. O valor calculado do teste $t$ para a igualdade de médias é de 1,14, rejeitando-se a hipótese alternativa de que a eficiência média das IES seja diferente. A diferença das médias é ligeiramente superior em 2015. A eficiência média das IES públicas é de 0,841 , ao passo que, para as IES privadas, este índice é igual a 0,809 . No entanto, o teste $t$ ainda rejeita a hipótese de que a eficiência média seja diferente entre as categorias administrativas $(t=1,552)$.

Avaliando-se a eficiência média dos alunos (EF1), a relação se inverte. Em 2012 e 2015, o desempenho dos alunos das instituiçôes privadas é vagamente superior ao de alunos das IES públicas. Em 2012, enquanto a eficiência dos estudantes das IES públicas é de 0,552 , os estudantes das IES privadas alcançam a eficiência média de 0,556. Em 2015, estes valores são iguais a 0,594 e 0,612 para alunos das IES públicas e privadas, respectivamente. Novamente, o teste $t$ não sugere a existência de diferença média dos grupos ( $t=0,938$ para 2012; e $t=1,403$ para 2015). 
Considerando-se o índice de eficiência 3, os resultados são bastante semelhantes entre as duas categorias administrativas, tanto em 2012 quanto em 2015. Em ambos os casos, o teste $t$ também rejeita a hipótese de que as médias sejam diferentes. Desagregando-se estes resultados, observa-se que o índice de eficiência é resultante, principalmente, da ineficiência dos alunos, considerando-se que, em 2012, a eficiência média de 0,447 é decomposta em 0,557 da parte dos alunos e em 0,801 das instituiçôes. Em 2015, a eficiência média de 0,498 é explicada pela eficiência de 0,601 dos alunos juntamente com a média de 0,828 das IES.

Os resultados completos para todos os índices calculados para IES públicas e privadas e o valor calculado dos testes t são apresentados na tabela 4. Além dos resultados já discutidos, a análise da eficiência de alunos e IES em relação à sua fronteira de categoria administrativa também indica não haver diferenças significativas entre o ensino público e o privado, independentemente do ano considerado.

TABELA 4

Eficiência média de alunos de ciências econômicas em IES públicas e privadas (2012 e 2015)

\begin{tabular}{|c|c|c|c|c|c|c|c|c|}
\hline \multirow{2}{*}{ Índice } & \multicolumn{4}{|c|}{2012} & \multicolumn{4}{|c|}{2015} \\
\hline & Público & Privado & Total & Teste $t$ & Público & Privado & Total & Teste $t$ \\
\hline EF1 & 0,552 & 0,564 & 0,557 & 0,938 & 0,594 & 0,612 & 0,601 & 1,403 \\
\hline EF2 & 0,449 & 0,451 & 0,450 & 0,133 & 0,501 & 0,501 & 0,501 & 0,099 \\
\hline EF3 & 0,448 & 0,446 & 0,447 & 0,148 & 0,499 & 0,495 & 0,498 & 0,096 \\
\hline EF4 & 0,814 & 0,799 & 0,807 & 0,807 & 0,844 & 0,818 & 0,834 & 1,278 \\
\hline EF5 & 0,811 & 0,790 & 0,801 & 1,140 & 0,841 & 0,809 & 0,828 & 1,552 \\
\hline EF6 & 0,997 & 0,989 & 0,993 & $10,385^{*}$ & 0,996 & 0,989 & 0,993 & $5,0925^{*}$ \\
\hline
\end{tabular}

Elaboração dos autores.

Obs.: ${ }^{*} p<0,01$.

Entre os índices calculados, o único que apresenta diferenças significativas de média é o índice de eficiência 6 , que considera as distâncias entre as fronteiras de determinada categoria administrativa e a fronteira global. E, embora em ambos os anos o EF6 das IES públicas seja significativamente superior às instituições privadas, esta diferença mantém-se muito pequena, na ordem de apenas 0,007.

Os resultados obtidos neste estudo não podem ser diretamente comparados com trabalhos que abordam o mesmo tema. Primeiramente, devido à desagregação entre o desempenho de alunos e instituiçóes que aqui foi realizado, enquanto os demais trabalhos encontrados tratam da questão somente sob o ponto de vista das universidades, o que pode levar a conclusóes errôneas, como apontado anteriormente. Em alguns casos, como em Coelho Júnior (2011), os dados são ainda mais agregados, segundo a Unidade da Federação (UF), de forma que as conclusóes obtidas devem ser generalizadas para toda a UF. 
Em segundo lugar, a escolha dos inputs e outputs não permite que se faça a comparação devida. Desde o trabalho pioneiro de Façanha e Marinho (2001) ao mais recente de Wagner (2011), a eficiência técnica das DMUs é avaliada segundo a quantidade de alunos que as IES eram capazes de matricular ou formar. Como exemplo, França (2004) utiliza dois modelos DEA diferentes. No primeiro deles, consideram-se três insumos - número de funçôes docentes, número de servidores e números de cursos ofertados; e dois produtos - total de alunos concluintes no ano e número de inscriçóes no vestibular. No segundo modelo, a quantidade de cursos ofertados passa de input a output, embora os resultados gerais destes modelos não sejam muito diferentes. Nesse sentido, este trabalho inova na tentativa de avaliar e quantificar a qualidade do ensino superior, com foco na comparação do resultado acadêmico entre as IES de diferentes categorias administrativas.

E, finalmente, deve-se considerar o enfoque exclusivo no curso de ciências econômicas realizado neste trabalho, enquanto os demais trabalhos avaliam a situação global das universidades, desconsiderando a heterogeneidade existente dentro das instituições, entre seus diferentes cursos.

Tendo em conta essas consideraçôes, ainda é preciso destacar que os resultados deste estudo divergem dos demais encontrados nesta área, que apontam para a maior eficiência entre as IES particulares (Façanha e Marinho, 2001; França, 2004; Coelho Júnior, 2011; Wagner, 2011). Nesse sentido, este trabalho se assemelha ao de Machado (2008), que não encontra evidências que indiquem a maior eficiência entre os tipos de instituiçóes avaliadas (universidades federais e pontifícias universidades católicas).

\section{CONSIDERAÇÕES FINAIS}

O trabalho teve como objetivo comparar o desempenho das instituiçóes de ensino superior brasileiras públicas e privadas que ministram o curso de economia, e, para tanto, foram realizados dois procedimentos. Na primeira parte, aplicou-se o modelo de regressão linear, tendo como base o questionário socioeconômico dos alunos graduandos no Enade de 2012 e 2015, visando ao controle destes fatores no desempenho dos alunos. A análise das regressóes estimadas mostra a relevância do conhecimento prévio do aluno em seu desempenho no ensino superior. Outros fatores que apresentaram relevância positiva na determinação da nota dos estudantes, em ao menos um dos períodos, foram a renda familiar, o nível educacional médio e superior dos pais, o ensino médio em escolas privadas e o hábito semanal de estudos. Por seu turno, as variáveis que apresentaram influência negativa foram: as regiôes geográficas (comparadas com a regiāo Sudeste), a idade (faixas etárias mais elevadas), o sexo feminino, a cor (estudantes negros) e o trabalho (duração semanal da jornada de trabalho). 
Em sequência, a aplicação da análise envoltória de dados, aplicando-se a metodologia proposta por Thanassoulis e Portela (2002), permitiu desagregar a eficiência global em dois fatores: um atribuído ao desempenho e motivação do aluno, e outro atribuído à instituição de ensino. Os resultados, em geral, não indicam a existência de diferenças significativas entre o desempenho público e o privado, seja do ponto de vista dos alunos (EF1), seja do ponto de vista das IES (EF5), em ambos os anos. Entre os índices avaliados, o único que apresentou média estatisticamente significativa entre as categorias administrativas foi o índice de eficiência 6 , que avalia a distância entre as fronteiras de categoria administrativa e a fronteira global das instituiçôes. Ainda assim, esta diferença é de pequena magnitude, a favor das instituiçóes públicas. Considerando-se o índice de eficiência 3, construído com base no desempenho simultâneo de alunos e instituiçôes, o resultado verificado é de que a maior parte da ineficiência calculada decorre do desempenho dos alunos.

Quando esses resultados são comparados com outros trabalhos na área, as conclusóes são divergentes; a maior parte deles confirma os resultados iniciais apontados por Façanha e Marinho (2001), atestando a maior eficiência das IES privadas. Apesar disso, as metodologias aplicadas por estes autores náo podem ser comparadas diretamente e, portanto, é necessário realizar as comparaçóes com cautela. É preciso destacar, também, que todos os resultados apresentados referem-se, com rigor, apenas aos alunos concluintes em ciências econômicas e suas respectivas instituições de ensino, nos anos de 2012 e 2015, não sendo possível generalizar as conclusōes para todo o universo do sistema educacional superior brasileiro.

Contextualizando os resultados do trabalho com a expansão recente do ensino superior citado na introdução, este estudo mostra que, ao menos no que se refere à eficiência de ensino no curso de ciências econômicas, a forma pela qual essa expansão ocorre é indiferente, ou seja, independe de o investimento ter origem privada ou pública. Ressalte-se, todavia, que é necessário encontrar novas maneiras de aumentar a eficiência dos alunos, atualmente baixa, quando comparada à eficiência das IES.

Finalmente, cabe destacar as possibilidades de ampliação deste trabalho. Primeiramente, como enfatizado, o escopo deste estudo restringe-se ao curso de economia. Dessa forma, abre-se aqui a necessidade da ampliação do escopo do estudo para maior abrangência de cursos, alunos e IES envolvidas, com maior abrangência temporal. Em segundo lugar, o estudo considerou a eficiência das instituiçóes de ensino, a partir do desempenho acadêmico de seus estudantes. Assim, não foram abordados outros aspectos institucionais que podem identificar os fatores que levam à eficiência dos cursos, como a formação dos professores e a estrutura física disponível. Trabalhos futuros podem contribuir com a literatura, ao incorporarem estes fatores externos aos alunos, realizando um mix de insumos relativos a alunos e instituiçóes, por meio de técnicas complementares à decomposição da análise envoltória de dados. 


\section{REFERÊNCIAS}

ABBOTT, M.; DOUCOULIAGOS, C. The efficiency of Australian universities: a data envelopment analysis. Economics of Education Review, v. 22, n. 1, p. 89-97, 2002.

AFONSO, A.; SANTOS, M. Public tertiary education expenditure in Portugal: a non-parametric efficiency analysis. Lisboa: ISEG-UTL Economics, 2004. (Working Paper, n. 5).

AHN, T.; CHARNES, A.; COOPER, W. W. Some statistical and DEA evaluations of relative efficiencies of public and private institutions of higher learning. Socio-Economic Planning Sciences, v. 22, n. 6, p. 259-269, 1988.

AHN, T.; SEIFORD, L. M. Sensitivity of DEA to models and variable sets in a hypothesis test setting: the efficiency of universitiy operations. In: IJIRI, Y. (Ed.). Creative and innovative approaches to the science of management. Westport: Quorum Books, 1993. 502p.

ALENCASTRO, L. D.; FOCHEZATTO, A. Eficiência técnica na gestão de recursos em instituiçôes privadas de ensino superior. Análise - Revista de Administraçáo da PUCRS, v. 17, n. 2, 2006.

BANKER, R. D.; CHARNES, A.; COOPER, W. W. Some models for estimating technical and scale inefficiencies in data envelopment analysis. Management Science, v. 30, n. 9, p. 1078-1092, 1984.

BELLONI, J. A. Uma metodologia de avaliaçáo da eficiência produtiva de universidades federais brasileiras. 2000. Tese (Doutorado) - Departamento de Engenharia de Produçáo e Sistemas, Universidade Federal de Santa Catarina, Florianópolis, 2000.

CHARNES, A.; COOPER, W. W.; RHODES, E. Measuring the efficiency of decision marking units. European Journal of Operational Research, v. 2, n. 6 , p. 429-444, 1978.

COELHO JÚNIOR, A. F. Avaliação das eficiências técnicas das Instituiçóes de Ensino Superior (públicas e privadas) por meio da data envelopment analysis (DEA) no período de 2004-2007. 2011. Dissertação (Mestrado) - Universidade Federal da Paraíba, João Pessoa, 2011.

ÇOKGEZEN, M. Technical efficiencies of faculties of economics in Turkey. Education Economics, v. 17, n. 1, p. 81-94, 2009.

CORBUCCI, P. R. Financiamento e democratização do acesso à educação superior no Brasil: da deserção do Estado ao projeto de reforma. Educaçáo e Sociedade, v. 25, n. 88 , p. $677-701,2004$. 
COSTA, E. M. et al. Eficiência e desempenho no ensino superior: uma análise da fronteira de produção educacional das IFES brasileiras. Revista de Economia Contemporânea, Rio de Janeiro, v.16, n. 3, set./dez. 2012.

EL-MAHGARY, S.; LAHDELMA, R. Data envelopment analysis: visualizing the results. European Journal of Operational Research, v. 83, n. 3, p. 700-710, 1995.

FAÇANHA, L. O.; MARINHO, A. Instituiçóes federais de ensino superior: modelos de financiamento e o incentivo à eficiência. Revista Brasileira de Economia, v. 53, n. 3, p. 357-386, 1999.

Instituiçóes de ensino superior governamentais e particulares: avaliação comparativa de eficiência. Rio de Janeiro: Ipea, 2001. (Texto para discussão, n. 813).

FRANÇA, J. M. F. Gestão produtiva em universidades públicas e privadas brasileiras: um estudo comparativo sobre eficiência técnica. In: COLÓQUIO INTERNACIONAL SOBRE GESTÃO UNIVERSITÁRIA NA AMÉRICA DO SUL, 4., 2004, Florianópolis, Universidade Federal de Santa Catarina (UFSC). Anais... Santa Catarina: UFSC, 2004.

GOLDSTEIN, H. Methods in school effectiveness research. School effectiveness and school improvement, v. 8, n. 4, p. 369-395, 1997.

GUIMARÁES, J. F.; SAMPAIO, B. The influence of family background and individual characteristics on entrance tests scores of Brazilian university students. In: ENCONTRO NACIONAL DE ECONOMIA, 30., 2007, Recife, Pernambuco, Anais... Recife: Anpec, 2007.

INEP - INSTITUTO NACIONAL DE ESTUDO E PESQUISAS EDUCACIONAIS ANÍSIO TEIXEIRA. Sinopses estatísticas da educação superior 2015. Brasília: Inep, 2016. Disponível em <https://bit.ly/3fFsnPM>.

JOHNES, J. Data envelopment analysis and its application to the measurement of efficiency in higher education. Economics of Education Review, v. 25, n. 3, p. 273-288, 2006a.

. Measuring teaching efficiency in higher education: an application of data envelopment analysis to economics graduates from UK Universities 1993. European Journal of Operational Research, v. 174, n. 1, p. 443-456, $2006 \mathrm{~b}$.

MANCEBÓN, M. J.; MUNIZZ, M. A. Private versus public high schools in Spain: disentangling managerial and programme efficiencies. Journal of the Operational Research Society, v. 59, n. 7, p. 892-901, 2008.

MARINHO, A.; RESENDE, M.; FAÇANHA, L. O. Brazilian federal universities: relative efficiency evaluation and data envelopment analysis. Revista Brasileira de Economia, v. 51, n. 4, p. 489-508, 1997. 
MCMILLAN, M. L.; DATTA, D. The relative efficiencies of Canadian universities: a DEA perspective. Canadian Public Policy, v. 24, n. 4, p. 485-511, 1998. MICHELOTTO, R. M.; COELHO, R. H; ZAINKO, M. A. S. A política de expansão da educação superior e a proposta de reforma universitária do governo. Educar, Curitiba, v. 28, p. 179-98, 2006.

MIRANDA, G. J. et al. Determinantes do desempenho acadêmico na área de negócios. Revista Meta: Avaliaçáo, v. 7, n. 20, p. 175-209, 2015.

MORICONI, G. M.; NASCIMENTO, P. A. M. M. Fatores associados ao desempenho dos concluintes de engenharia no Enade 2011. Estudos em Avaliaçáo Educacional, v. 25, n. 57, p. 248-278, 2014.

NUINTIN, A. A. et al. Eficiência da aplicação de recursos públicos nas universidades federais. 2014. Doutorado (Tese) - Universidade Federal de Lavras, Minas Gerais. In: CONGRESSO BRASILEIRO DE CUSTOS-ABC, 21., Natal, Rio Grande do Norte, 2014. Anais... Natal: ABC, 2014.

OSÓRIO, A.; MENDES, V.; REBELO, J. A eficiência econômica nas empresas públicas e privadas: uma análise comparada. In: CONGRESSO DOS ECONOMISTAS DA LÍNGUA PORTUGUESA, 3., Macau, Rio Grande do Norte, 1998. Anais... Macau: Congresso dos Economistas da Língua Portuguesa, 1998.

PEÑA, C. R. Um modelo de avaliação da eficiência da administração pública através do método análise envoltória de dados (DEA). RAC - Revista de Administraçáo Contemporânea, v. 12, n. 1, p. 83-106, 2008.

PORTELA M. C.; THANASSOULIS, E. Decomposing school and school-type efficiency. European Journal of Operational Research, v. 132, n. 2, p. 357-373, 2001.

PFEIFER, M.; GIARETA, P. F. Expansão da educação superior no Brasil: panorama e perspectiva para a formação de professores. In: CONGRESSO NACIONAL DE EDUCAÇÃO (EDUCERE), 9.; ENCONTRO SUL BRASILEIRO DE PSICOPEDAGOGIA (ESCP), 3., 2009, Curitiba, Paraná. Anais... Curitiba: EDUCERE; ESCP, 2009.

RHODES, E. L.; SOUTHWICK, L. Determinants of efficiency in public and private universities. Columbia: University of South Carolina, 1986.

SAMPAIO, B.; GUIMARÁES, J. Diferenças de eficiência entre ensino público e privado no Brasil. Economia Aplicada, São Paulo, v. 13, n. 1, p. 45-68, 2009.

SOUSA, M. C. S.; STOSIC, B. D. Technical efficiency of the Brazilian municipalities: correcting nonparametric frontier measurements for outliers. Journal of Productivity Analysis, v. 24, n. 2, p. 157-181, 2005. 
. Detecção de outliers em modelos não paramétricos: o método Jackstrap ampliado. In: BOUERI, R.; ROCHA, F.; RODOPOULOS, F. M. A (Orgs.). Avaliaçáo da qualidade do gasto público e mensuração da eficiência. Brasília: Secretaria do Tesouro Nacional, 2015.

STOSIC, B.; SOUSA M. C. S. Jackstrapping DEA scores for robust efficiency measurement. In: ENCONTRO BRASILEIRO DE ECONOMETRIA (SBE), 25., Bahia, Porto Seguro, 2003. Anais... Porto Seguro: SBE, 2003.

THANASSOULIS, E; PORTELA, M. C. School outcomes: sharing the responsibility between pupil and school. Education Economics, v. 10, n. 2, p. 183-207, 2002. WAGNER, P. A. R. Análise de eficiência das instituiçóes de ensino superior pública e privada. Dissertação (Mestrado) - Universidade Católica de Brasília, Brasília, 2011.

WARNING, S. Performance differences in German higher education: empirical analysis of strategic groups. Review of Industrial Organization, v. 24, n. 4, p. 393-408, 2004. 


\section{APÊNDICE A}

\section{GRÁFICO A. 1}

Fronteira de eficiência dos alunos concluintes em economia (2012)

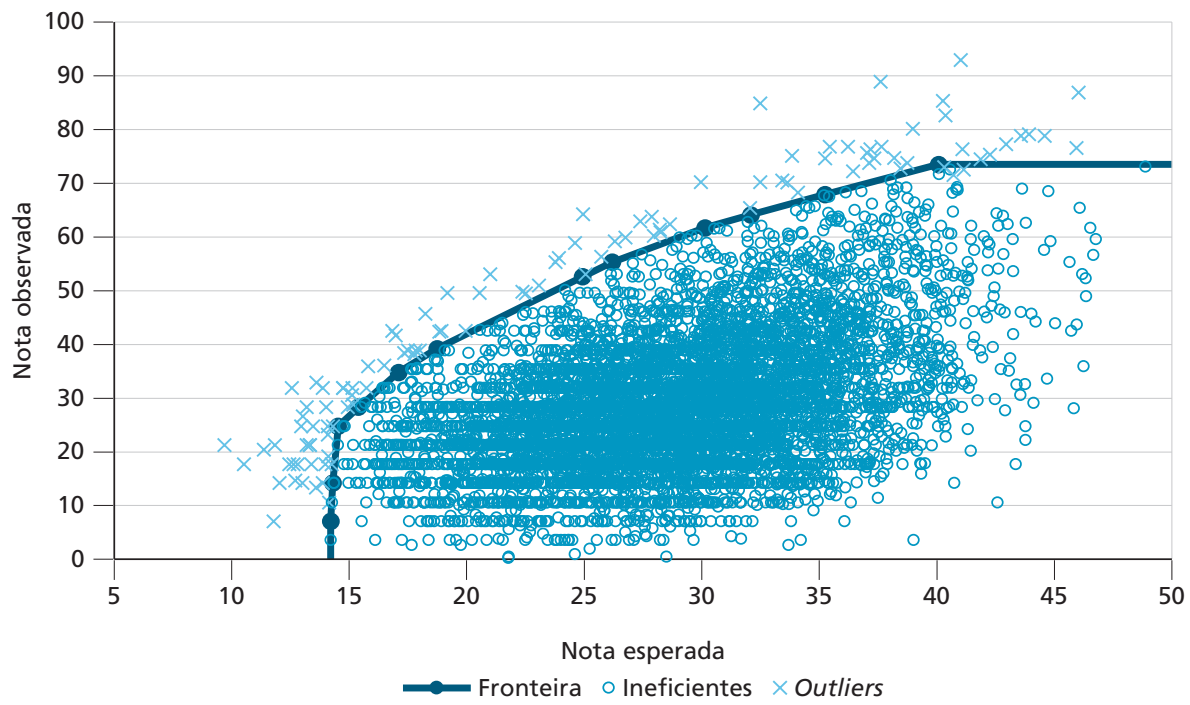

Elaboração dos autores. 


\section{APÊNDICE B}

GRÁFICO B.1

Fronteira de eficiência dos alunos concluintes em economia (2015)

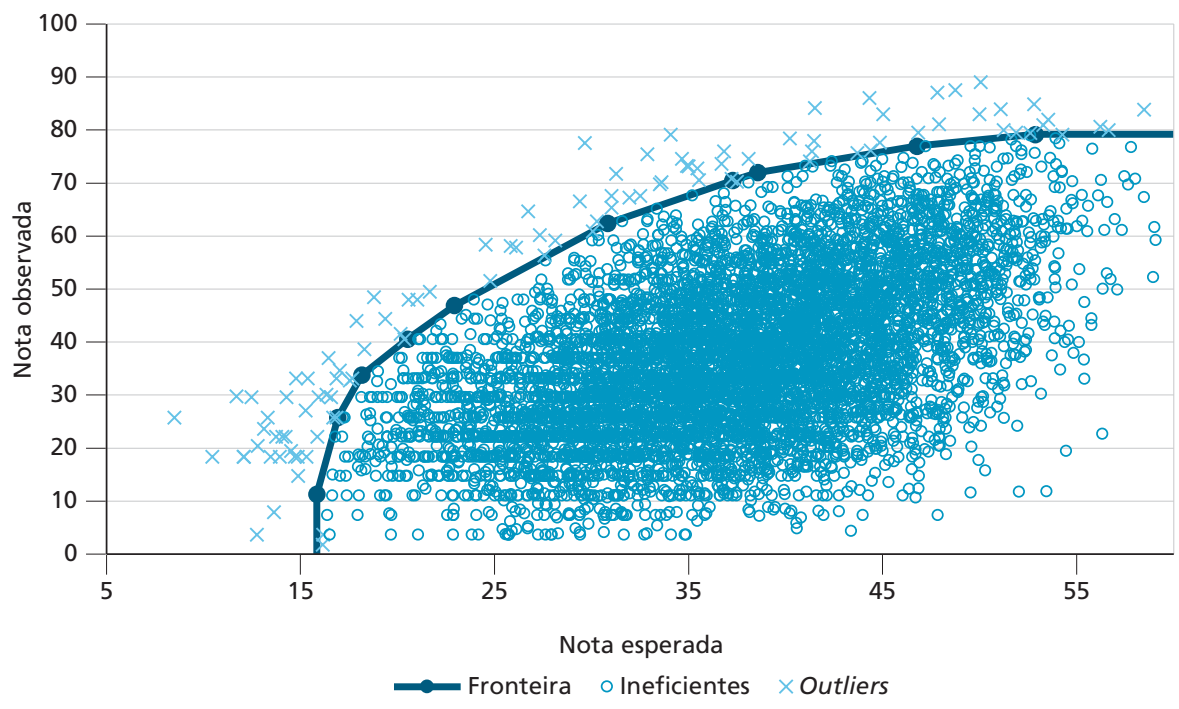

Elaboração dos autores.

Data de submissão: 21/3/2017

Primeira decisão editorial em: 5/3/2018

Última versão recebida em: 15/8/2018

Aprovação final em: 27/8/2018 